\title{
Price Forecasting of Cotton in Krishna and Kurnool Districts of Andhra Pradesh
}

\author{
Manne Sri Sandhya* \\ SRF, SV Agricultural College, ANGRAU, Tirupati, India \\ *Corresponding author
}

\section{A B S T R A C T}

\begin{tabular}{|l|}
\hline Key w ord s \\
Price Forecasting, \\
Cotton
\end{tabular}

An attempt was made to forecast the prices of cotton in Andhra Pradesh, India. The BoxJenkins procedure is concerned in fitting a mixed Auto Regressive Integrated Moving Average (ARIMA) model to a given set of data. ARIMA model is a combination of AR and MA models with suitable order of differencing. The first step in developing ARIMA model is to examine data for stationarity. A model was identified for the prices of cotton in Kurnool district. The monthly wholesale prices from April 2007 to March 2019 were used to estimate the ACF and PACF. The price data were tested for stationarity. It can be clearly seen from the table that there is fall in the values of ACF from 0.926 to 0.428.It was observed from the analysis that the model is valid by observing the Mean Absolute Percentage Error (MAPE) and Theil U statistics. Average MAPE was 10.15 per cent for the year 2019 and Theil $\mathrm{U}$ was greater than 1 which showed the model $(1,1,3)$ is best for forecasting. A model was identified for the prices of cotton in Krishna market. The monthly wholesale prices from April 2007 to March 2019 were used to estimate the ACF and PACF. The price data were tested for stationarity. It can be clearly seen from the table that there is fall in the values of ACF from 0.926 to 0.618.It was observed from the analysis as mentioned in the table 4.20 that the model is valid by observing the Mean Absolute Percentage Error (MAPE) and Theil U statistics. Average MAPE was 7.54 percent for the year 2019.

\section{Introduction}

Cotton is an important cash crop among the major commercial crops grown in India as well as in Andhra Pradesh. Cotton, popularly known as 'White Gold', dominates India's cash crops, and makes up 65 per cent of the raw material requirements of the Indian textile industry. India is the third largest cotton producer in the world followed by China and the United States, accounting for about 25 per cent of the world acreage but only 14 per cent of world production.

The major cotton growing States are Maharashtra, Gujarat, Andhra Pradesh, Punjab, Haryana, Madhya Pradesh, Rajasthan, Karnataka and Tamil Nadu. Among the cotton growing states, Andhra Pradesh occupies third position in the country in respect of area, production and productivity of cotton. The advent of Bt cotton over the last seven years 
has coincided with more than doubling of yield(James,2008). It was observed that cotton production in Andhra Pradesh is fluctuating with the vagaries of rainfall. Over the years, it has witnessed several ups and downs in area, production and productivity.

Agricultural marketing plays an important role not only in stimulating production and consumption, but in accelerating the pace of economic development. Insect pests are one of the major limiting factors in cotton production. India is becoming major exporter of cotton given its competitiveness in producing cotton(Reddy et.al,2012: Rani et al.,2014) About 1300 species of Insects have been reported on cotton worldwide(Matthews and Tunstall, 1994). An efficient marketing system ensures higher levels of income for the farmers and widen the market for the products by taking them to remote corners of the country and the worldwide.

Fluctuations in market arrivals largely contribute to the price instability of the produce. In order to device appropriate ways and means for reducing price fluctuations of agricultural commodities, there is a need to have a thorough understanding of price behaviour over time and over space.

This information is further strengthened through forecasts of prices in future markets. Such an analysis is also useful to farmers in order to decide the optimum time for disposing their produce to their best advantage. Proper planning in disposing of the produce by the farmer alone can considerably increase their income without incurring much additional cost.

The present study is aimed to forecast the prices of cotton in the major cotton producing districts of Andhra Pradesh i.e., Kurnool and Krishna districts.

\section{Forecasting of Prices}

The Box-Jenkins procedure is concerned in fitting a mixed Auto Regressive Integrated Moving Average (ARIMA) model to a given set of data. The main objective in fitting ARIMA model is to identify the stochastic process of the time series and predict the future values accurately.

\section{Auto Regressive Integrated Moving Average (ARIMA) Model}

ARIMA model is a combination of $\mathrm{AR}$ and MA models with suitable order of differencing. The first step in developing ARIMA model is to examine data for stationarity.

The ARIMA (p,d,q) model is then formulated as

Zt-b1Zt-1-.... -bpZt-p =Ut-Ø1 Ut-1- $\ldots$ $\emptyset \mathrm{qUt}-\mathrm{q}$

Where, $\mathrm{Zt}=\mathrm{Yt}_{-}{ }^{\bar{Y}}$ (deviation of Yt from mean Y).

The formulation of ARIMA model requires Auto Correlation Function (ACF) and Partial Auto Correlation Function (PACF).The ACF can be generated on the basis of auto correlation coefficients $\left(\rho_{j}\right)$ corresponding to different lags $(\mathrm{j})$, defined as;

$\rho_{j}=\frac{\Sigma Y_{t} Y_{t-j}-\frac{1}{n}\left[\left(\Sigma Y_{t}\right)\left(\Sigma Y_{t-j}\right)\right]}{\Sigma Y_{t}^{2}-\frac{1}{n}\left(\Sigma Y_{t}\right)^{2}} \mathrm{~J}=1$

The PACF can be obtained through the Yulewalker's equations on the basis of $\rho$ 's. The Yule-walker's equations can be described as

$\rho_{j=} \phi_{k 1} \rho_{j-1}+\ldots+\varnothing \mathrm{k}(\mathrm{k}-1)^{\rho_{j-k+1}} \varnothing$ $\mathrm{kk}^{\rho_{j-k}} ; \mathrm{j}=1, \ldots \mathrm{K}$ 
Where,

Ø's = Partial Auto Correlation coefficients

$\rho_{j}=$ Auto correlations corresponding to the jth lag.

\section{Stationary time series model}

\section{An Auto Regressive Process (p, o, o)}

If the observation Yt depends on previous observation and error term Ut it is called auto regressive process (AR process).

$\mathrm{Yt}=\mathrm{a}+\mathrm{b} 1 \mathrm{Yt}-1+\mathrm{Ut}$

Where,

$\mathrm{Yt}=$ The value of variable for forecasting at time ' $t$ ' (Price, in the study)

$\mathrm{a}=$ Constant

b1 $=$ Regression coefficient

$\mathrm{Ut}=$ Random error

\section{A Moving Average Process $(\mathbf{0 , 0 , q )}$}

If the observation Yt depends on the error term ut and also on one or more previous error terms (ut's) then we have moving average MA(q) process.

$\mathrm{Yt}={ }^{\mu}+\beta_{s} \mathrm{u}_{t}+\beta_{1} \mathrm{u}_{t-1}+\beta_{2} \mathrm{u}_{t-2}+\ldots+\beta_{q} \mathrm{u}_{t-q}$

Where,

$\mathrm{Yt}=$ The value of the variable for forecasting at time' $t$ ' (i.e., price)

$\mu=$ Constant

$\mathrm{u}=$ Stochastic error term

An Auto Regressive Moving Average (ARMA) Model

In the model Yt depends on AR as well as MA variables and can be specified

$$
\text { As } Y_{t}=\theta+a_{1} Y_{t-1}+\beta_{0} \mu_{t}+\beta_{1} \mu_{t-1}
$$

\section{An Auto Regressive Integrated Moving} Average (ARIMA) model

If the time series data is integrated of order 1 i.e., I (1), its first differences are I (0), that is stationary.

Similarly sometime series data is I (2). Its second difference is I (0). In general, if a time series is $I(d)$, after the differencing it $d$ times we obtain an I (0) series.

The main stages in setting up a Box-Jenkins forecasting model are as follows:

1. Identification

2. Estimating the parameters

3. Diagnostic checking and

4. Forecasting

\section{Identification of models}

A good starting point for time series analysis is a graphical plot of the data.

It helps to identify the presence of trends. Before estimating the parameter (p, q) of model, the data are not examined to decide about the model which best explains the data.

\section{Estimation of parameters}

After tentatively identifying the suitable model, next step is to obtain least squares estimates of the parameters such that the error sum of squares is minimum.

$\mathrm{S}(\Theta)=,n \sum_{k=1}^{n} e_{t}^{2}$

Where,

$\mathrm{t}=1,2,3 \ldots \mathrm{n}$ 


\section{Diagnostic checking}

After having estimated the parameters of a tentatively identified ARIMA model, it is necessary to do diagnostic checking to verify that the model is adequate.

Here selection of model was done by criteria like Schwarz Bayesian Information Criterion (SBIC), R2 values.

\section{Shwarz Bayesian Criterion (SBC)}

In statistics, the Bayesian information criterion (BIC) or Shwarz criterion (also SBC, SBIC) is a criterion for model selection among a finite set of models.

It is based, in part, on the likelihood function, and it is closely related to Akaike information criterion (AIC).

The formula for the BIC is

$$
\text { - 2. } \ln \mathrm{p}(\mathrm{x} / \mathrm{k}) \approx \mathrm{BIC}=-2 \cdot \ln \mathrm{L}+\mathrm{k} \ln (\mathrm{n})
$$

Under the assumption that the model errors or disturbances are independent and identically distributed according to a normal distribution and that the boundary condition that the derivative of the $\log$ likelihood with respect to the true variance is zero.

$\mathrm{BIC}=\mathrm{n} \cdot \operatorname{In} \sigma_{e}^{2}+k \cdot \operatorname{In}(n)$

The error variance in this case is defined as

$\sigma_{\rho}^{2}=\sum_{n}^{1} \sum_{i=1}^{n}\left(x_{i}-\bar{x}\right)^{2}$

\section{$R^{2}$-Criteria}

$R^{2}$ is a statistic that will give information about the goodness of fit of a model.
The most general definition of the coefficient of determination is

$R^{2}=1-\frac{E S S}{T S S}$

ESS-Error Sum of Squares

TSS-Total Sum of Squares

\section{Forecasting}

After satisfying about the adequacy of the fitted model, it can be used for forecasting. Forecasts based on the model.

$(1-\varnothing \mathrm{B})=\left(1-\Phi_{\mathrm{B}}\right)^{e_{t}}$

were computed for up to 2 years ahead. The above model gives the forecasting equation as

$\mathrm{Yt}=\varnothing \mathrm{yt}-1+$ et $-\Theta^{e_{t-1}}$

Given the data up to time ' $t$ ' the optional forecast of $Y$ model at the $t$ is the conditional expectation of $\mathrm{Yt}+1 . \mathrm{It}$ allows, in particular, that

$e_{t=\mathrm{Yt}-\mathrm{Yt}-1}$

"The errors $e_{\text {tin fact the forecast errors for }}$ unit lead time.

\section{Results and Discussion}

Forecasting of prices for cotton in Kurnool market

\section{Identification of the model}

A model was identified for the prices of cotton in Kurnool district. The monthly wholesale prices from April 2007 to March 2019 were used to estimate the ACF and PACF. The price data were tested for stationarity. It can be clearly seen from the 
table that there is fall in the values of ACF from 0.926 to 0.428 . As observed from the analysis many values are different from zero and fall outside 95 percent confidence interval, indicating the price of cotton to be non-stationary. The analysis of partial autocorrelation coefficients of cotton have been depicted in the table 1. The graphical presentation of ACF and PACF of table are given in Fig. 1. The partial autocorrelation function (PACF) took a fall after the $1^{\text {st }}$ lag period from 0.926 to 0.149 , from which the non-stationarity of the series can be inferred.

The table 1 shows that the autocorrelation and partial autocorrelation functions at lag 16 were significantly different from zero and fall outside the 95 per cent confidence interval. $1^{\text {st }}$ difference of price data of cotton was done to make the series stationary.

The Augmented Dickey Fuller based unit root test procedure was carried out to check whether the price series of cotton were stationary or not. From the table 2, it is observed that Augmented Dickey Fuller test values are above the critical value $(1 \%)$ given by MacKinnon statistical table at levels showing that the series are non-stationary by the presence of unit root. After the $1^{\text {st }}$ difference, the series become stationary which means the calculated values for the market are less than the critical value (1\%) and free from the consequence of unit root.

The results of Augmented Dickey Fuller (ADF) unit root test for cotton showed that the level data were not stationary but their $1^{\text {st }}$ differences showed stationarity.

The graphical representation of $\mathrm{ACF}$ and PACF is given in the fig. 1 which confirms the results. Therefore, the value of $d$ in the ARIMA model was unity $(1)$ because the $1^{\text {st }}$ difference was carried out only once to attain stationarity.

\section{Model estimation}

The best model was chosen from the various ARIMA models viz, ARIMA(1,1,3); ARIMA (3,1,3); $\operatorname{ARIMA}(4,1,3) \quad$;ARIMA(2,1,1); $\operatorname{ARIMA}(3,1,4)$ on the basis of least Akaike Information Criterion (AIC) and Schwarz Bayesian Criterion (SBC). The models as identified above were estimated through the Marquardt procedure using SPSS 7.5 and SPSS 20 version of the SPSS package.

On comparing the alternative models on the basis of statistics such as Akaike Information Criterion and Schwarz Bayesian Criterion (SBC), it was inferred that both AIC(-191.40) and SBC (179.67) were the least for ARIMA $(1,1,3)$ model from table 3 . Hence ARIMA $(1,1,3)$ was the most representative model for the price of cotton in Kurnool market.

\section{Diagnostic checking}

The model verification is concerned with the residuals of the model to see if they still contain any systematic pattern which further could be removed in order to improve the chosen ARIMA, which has been analyzed by examining the autocorrelations and partial autocorrelation functions of various orders of the residuals of ARIMA $(1,1,3)$ up-to 16 lags were analyzed and presented in the table 4. The values of ACF and PACF varies from 0.008 to 0.054 which shows the auto correlation and partial auto correlation functions at lag 16 were significantly different from zero and fall within the $95 \%$ confidence interval.

The graphical representation of ACF and PACF is given in the fig. 2 which also confirms the above results that there is no ACF and PACF that lies outside the interval. So we can say that the residual series is stationary. Thus it could be concluded that the selected ARIMA $(1,1,3)$ model was 
appropriate for forecasting the prices of cotton during the period under study.

It was observed from the analysis as mentioned in the table 5 that the model is valid by observing the Mean Absolute
Percentage Error (MAPE) and Theil U statistics. Average MAPE was 10.15 percent for the year 2019 and Theil $U$ was greater than 1 which showed the model $(1,1,3)$ is best for forecasting.

Table.1 Autocorrelation and Partial Correlation Coefficient of cotton in Kurnool market (level)

\begin{tabular}{|l|l|l|l|c|c|}
\hline Lag & \multicolumn{2}{|c|}{ Autocorrelation Coefficient } & Box-Ljung & \multicolumn{2}{c|}{ Partial Autocorrelation Coefficient } \\
\cline { 2 - 4 } & Value & S.E & & Value & S.E \\
\hline $\mathbf{1}$ & 0.926 & 0.082 & 126.185 & 0.926 & 0.083 \\
\hline $\mathbf{2}$ & 0.838 & 0.082 & 230.232 & -0.141 & 0.083 \\
\hline $\mathbf{3}$ & 0.764 & 0.082 & 317.362 & 0.064 & 0.083 \\
\hline $\mathbf{4}$ & 0.723 & 0.082 & 395.827 & 0.170 & 0.083 \\
\hline $\mathbf{5}$ & 0.689 & 0.081 & 467.695 & -0.002 & 0.083 \\
\hline $\mathbf{6}$ & 0.647 & 0.081 & 531.553 & -0.055 & 0.083 \\
\hline $\mathbf{7}$ & 0.607 & 0.081 & 588.029 & .0042 & 0.083 \\
\hline $\mathbf{8}$ & 0.575 & 0.080 & 639.114 & 0.044 & 0.083 \\
\hline $\mathbf{9}$ & 0.552 & 0.080 & 686.607 & 0.023 & 0.083 \\
\hline $\mathbf{1 0}$ & 0.532 & 0.080 & 730.995 & 0.012 & 0.083 \\
\hline $\mathbf{1 1}$ & 0.523 & 0.080 & 774.157 & 0.104 & 0.083 \\
\hline $\mathbf{1 2}$ & 0.496 & 0.079 & 813.310 & -0.131 & 0.083 \\
\hline $\mathbf{1 3}$ & 0.464 & 0.079 & 847.830 & -0.011 & 0.083 \\
\hline $\mathbf{1 4}$ & 0.439 & 0.079 & 878.988 & 0.068 & 0.083 \\
\hline $\mathbf{1 5}$ & 0.422 & 0.078 & 907.987 & -0.008 & 0.083 \\
\hline $\mathbf{1 6}$ & 0.428 & 0.078 & 938.111 & 0.149 & 0.083 \\
\hline
\end{tabular}

The underlying process assumed is independent (white noise)

Table.2 ADF unit root test for prices of cotton in Kurnool market

\begin{tabular}{|l|l|l|}
\hline ADF test value & Augmented Dickey Fuller (ADF) & Critical value (1\%) \\
\hline Level & $-2.206(0.2049)$ & -3.48 \\
\hline $\mathbf{1}^{\text {st }}$ difference & s-9.082 $(0.000)$ & \\
\hline ** significant at $1 \%$ level \\
Note: Figures in parenthesis indicate Mackinnon (1996) p- value
\end{tabular}

Table.3 ARIMA models selected for forecasting the price of cotton based on least AIC \&SBC at Kurnool market

\begin{tabular}{|l|c|c|c|}
\hline Model & Log I & AIC & SBC \\
\hline ARIMA(1,1,3) & 155.29 & -191.40 & 179.67 \\
\hline ARIMA (3,1,3) & 156.81 & -190.84 & -175.20 \\
\hline ARIMA(4,1,3) & 157.46 & -190.33 & -172.73 \\
\hline ARIMA(2,1,1) & 153.32 & -190.16 & -180.38 \\
\hline ARIMA(3,1,4) & 156.89 & -189.60 & -172.01 \\
\hline
\end{tabular}


Table.4 Autocorrelation Coefficient and Partial Correlation coefficient of residual of ARIMA $(1,1,3)$ model for cotton price in Kurnool market

\begin{tabular}{|l|c|c|c|c|c|}
\hline \multirow{2}{*}{ Lag } & \multicolumn{2}{|c|}{$\begin{array}{c}\text { Autocorrelation } \\
\text { Coefficient }\end{array}$} & \multirow{2}{*}{$\begin{array}{c}\text { Box- } \\
\text { Ljung }\end{array}$} & \multicolumn{2}{c|}{$\begin{array}{c}\text { Partial Autocorrelation } \\
\text { Coefficient }\end{array}$} \\
\cline { 2 - 3 } $\mathbf{1}$ & Value & $\mathbf{S . E}$ & & Value & S.E \\
\hline $\mathbf{2}$ & -0.008 & 0.083 & 0.008 & -0.008 & 0.084 \\
\hline $\mathbf{3}$ & -0.015 & 0.082 & 0.040 & -0.015 & 0.084 \\
\hline $\mathbf{4}$ & 0.005 & 0.082 & 0.044 & 0.005 & 0.084 \\
\hline $\mathbf{5}$ & 0.040 & 0.082 & 0.280 & 0.040 & 0.084 \\
\hline $\mathbf{6}$ & 0.077 & 0.082 & 1.179 & 0.078 & 0.084 \\
\hline $\mathbf{7}$ & 0.011 & 0.081 & 1.198 & 0.014 & 0.084 \\
\hline $\mathbf{8}$ & -0.115 & 0.081 & 3.229 & -0.114 & 0.084 \\
\hline $\mathbf{9}$ & 0.000 & 0.081 & 3.229 & -0.005 & 0.084 \\
\hline $\mathbf{1 0}$ & 0.048 & 0.080 & 3.582 & 0.040 & 0.084 \\
\hline $\mathbf{1 1}$ & -0.072 & 0.080 & 4.386 & -0.078 & 0.084 \\
\hline $\mathbf{1 2}$ & 0.144 & 0.080 & 7.644 & 0.155 & 0.084 \\
\hline $\mathbf{1 3}$ & -0.044 & 0.079 & 7.948 & -0.028 & 0.084 \\
\hline $\mathbf{1 4}$ & -0.031 & 0.079 & 8.104 & -0.031 & 0.084 \\
\hline $\mathbf{1 5}$ & -0.038 & 0.079 & 8.341 & -0.056 & 0.084 \\
\hline $\mathbf{1 6}$ & -0.129 & 0.079 & 11.043 & -0.140 & 0.084 \\
\hline & 0.054 & 0.078 & 11.527 & 0.050 & 0.084 \\
\hline
\end{tabular}

Table.5 One step ahead in Forecasting for prices of cotton in Kurnool market

\begin{tabular}{|l|c|c|}
\hline Months & Actual price & Predicted price \\
\hline March 18 & 5169 & \\
\hline April 18 & 4339 & 5810.076 \\
\hline May 18 & 4699 & 5844.738 \\
\hline June & 5669 & 5879.584 \\
\hline July 18 & 6099 & 5914.625 \\
\hline August18 & 6176 & 5949.869 \\
\hline September18 & 6108 & 5985.321 \\
\hline October 18 & 5789 & 6020.982 \\
\hline November 18 & 5780 & 6056.854 \\
\hline December 18 & 5590 & 6092.94 \\
\hline January 19 & 5510 & 6129.241 \\
\hline February 19 & 5520 & 6165.757 \\
\hline March19 & 5620 & 6202.492 \\
\hline MAPE & & 10.15 \\
\hline U1 & & 0.05642 \\
\hline U2 & & 1.43 \\
\hline
\end{tabular}


Table.6 Autocorrelation and Partial Correlation Coefficient of cotton in Krishna market (level)

\begin{tabular}{|l|c|c|c|c|c|}
\hline Lag & \multicolumn{2}{|c|}{$\begin{array}{c}\text { Autocorrelation } \\
\text { Coefficient }\end{array}$} & $\begin{array}{c}\text { Box- } \\
\text { Ljung }\end{array}$ & \multicolumn{2}{c|}{$\begin{array}{c}\text { Partial Autocorrelation } \\
\text { Coefficient }\end{array}$} \\
\cline { 2 - 5 } & Value & S.E & & Value & S.E \\
\hline $\mathbf{1}$ & 0.926 & 0.082 & 126.010 & 0.926 & 0.083 \\
\hline $\mathbf{2}$ & 0.851 & 0.082 & 233.348 & -0.039 & 0.083 \\
\hline $\mathbf{3}$ & 0.835 & 0.082 & 337.207 & 0.363 & 0.083 \\
\hline $\mathbf{4}$ & 0.825 & 0.082 & 439.474 & 0.042 & 0.083 \\
\hline $\mathbf{5}$ & 0.795 & 0.081 & 535.019 & -0.006 & 0.083 \\
\hline $\mathbf{6}$ & 0.764 & 0.081 & 624.002 & 0.030 & 0.083 \\
\hline $\mathbf{7}$ & 0.763 & 0.081 & 713.373 & 0.166 & 0.083 \\
\hline $\mathbf{8}$ & 0.755 & 0.080 & 801.529 & -0.048 & 0.083 \\
\hline $\mathbf{9}$ & 0.721 & 0.080 & 882.576 & -0.058 & 0.083 \\
\hline $\mathbf{1 0}$ & 0.702 & 0.080 & 959.981 & 0.090 & 0.083 \\
\hline $\mathbf{1 1}$ & 0.732 & 0.080 & 1044.599 & 0.279 & 0.083 \\
\hline $\mathbf{1 2}$ & 0.754 & 0.079 & 1135.160 & 0.040 & 0.083 \\
\hline $\mathbf{1 3}$ & 0.699 & 0.079 & 1213.523 & -0.376 & 0.083 \\
\hline $\mathbf{1 4}$ & 0.637 & 0.079 & 1279.183 & -0.101 & 0.083 \\
\hline $\mathbf{1 5}$ & 0.624 & 0.078 & 1342.724 & 0.044 & 0.083 \\
\hline $\mathbf{1 6}$ & 0.618 & 0.078 & 1405.430 & 0.015 & 0.083 \\
\hline
\end{tabular}

The underlying process assumed is independent (white noise)

Table.7 ADF unit root test for prices of cotton in Krishna market

\begin{tabular}{|c|c|c|}
\hline ADF test value & Augmented Dickey Fuller (ADF) & Critical value(1\%) \\
\hline Level & $-1.343(0.6081)$ & \multirow[t]{2}{*}{-3.48} \\
\hline $1^{\text {st }}$ difference & $-5.416(0.000)$ & \\
\hline
\end{tabular}

Table.8 ARIMA models selected for forecasting the price of cotton based on least AIC \&SBC at Krishna market

\begin{tabular}{|l|c|c|c|}
\hline Model & Log l & AIC & SBC \\
\hline ARIMA(4,1,4) & 168.66 & -203.42 & -183.69 \\
\hline ARIMA (2,1,4) & 162.62 & -198.23 & -182.59 \\
\hline ARIMA(3,1,4) & 161.76 & -195.85 & -178.26 \\
\hline ARIMA(1,1,3) & 157.74 & -194.54 & -182.91 \\
\hline ARIMA(4,1,3) & 157.05 & -189.80 & -172.21 \\
\hline
\end{tabular}


Table.9 Auto-Correlation Coefficient and Partial Correlation coefficient of residual of ARIMA $(4,1,4)$ model for cotton price in Krishna market

\begin{tabular}{|l|c|c|c|c|c|}
\hline \multirow{2}{*}{ Lag } & \multicolumn{2}{|c|}{$\begin{array}{c}\text { Auto-Correlation } \\
\text { Coefficient }\end{array}$} & \multirow{2}{*}{$\begin{array}{c}\text { Box- } \\
\text { Ljung }\end{array}$} & \multicolumn{2}{c|}{$\begin{array}{c}\text { Partial Autocorrelation } \\
\text { Coefficient }\end{array}$} \\
\cline { 2 - 3 } & Value & S.E & & Value & S.E \\
\hline $\mathbf{1}$ & 0.015 & 0.083 & 0.032 & 0.015 & 0.084 \\
\hline $\mathbf{2}$ & 0.014 & 0.082 & 0.062 & 0.014 & 0.084 \\
\hline $\mathbf{3}$ & -0.018 & 0.082 & 0.110 & -0.018 & 0.084 \\
\hline $\mathbf{4}$ & -0.026 & 0.082 & 0.212 & -0.026 & 0.084 \\
\hline $\mathbf{5}$ & -0.055 & 0.082 & 0.662 & -0.054 & 0.084 \\
\hline $\mathbf{6}$ & -0.035 & 0.081 & 0.843 & -0.033 & 0.084 \\
\hline $\mathbf{7}$ & -0.184 & 0.081 & 6.007 & -0.184 & 0.084 \\
\hline $\mathbf{8}$ & -0.039 & 0.081 & 6.236 & -0.039 & 0.084 \\
\hline $\mathbf{9}$ & 0.026 & 0.080 & 6.341 & 0.026 & 0.084 \\
\hline $\mathbf{1 0}$ & -0.023 & 0.080 & 6.421 & -0.036 & 0.084 \\
\hline $\mathbf{1 1}$ & 0.080 & 0.080 & 7.432 & 0.068 & 0.084 \\
\hline $\mathbf{1 2}$ & 0.524 & 0.079 & 50.901 & 0.527 & 0.084 \\
\hline $\mathbf{1 3}$ & 0.014 & 0.079 & 50.931 & 0.018 & 0.084 \\
\hline $\mathbf{1 4}$ & -0.018 & 0.079 & 50.985 & -0.091 & 0.084 \\
\hline $\mathbf{1 5}$ & -0.001 & 0.079 & 50.985 & 0.024 & 0.084 \\
\hline $\mathbf{1 6}$ & -0.021 & 0.078 & 51.057 & 0.010 & 0.084 \\
\hline
\end{tabular}

Table.10 One step ahead in Forecasting for prices of cotton in Krishna market

\begin{tabular}{|l|c|c|}
\hline Months & Actual price & Predicted price \\
\hline March 18 & 4600 & \\
\hline April 18 & 4700 & 4994.766 \\
\hline May 18 & 4400 & 4874.78 \\
\hline June & 4300 & 4890.227 \\
\hline July 18 & 4900 & 5058.767 \\
\hline August18 & 5100 & 5071.276 \\
\hline September18 & 4700 & 4920.622 \\
\hline October 18 & 4800 & 4926.538 \\
\hline November 18 & 4600 & 5106.478 \\
\hline December 18 & 4600 & 5146.387 \\
\hline January 19 & 4550 & 5023.126 \\
\hline February 19 & 4575 & 5048.976 \\
\hline March19 & 5000 & 5243.274 \\
\hline MAPE & & 7.54 \\
\hline U1 & & 0.0401 \\
\hline U2 & & 1.38 \\
\hline
\end{tabular}


Fig.1 Autocorrelation and Partial Autocorrelation coefficient of $1^{\text {st }}$ difference series of cotton prices in Kurnool market
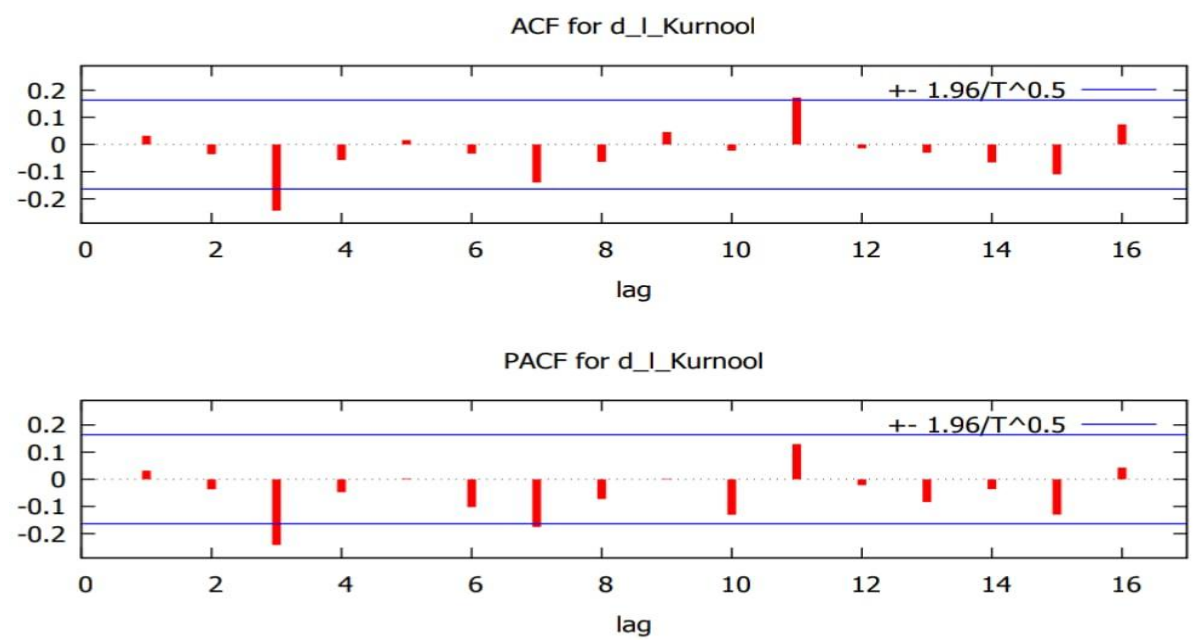

Fig.2 Autocorrelation and Partial Autocorrelation of residual of ARIMA $(1,1,3)$ model for market of cotton in Kurnool market
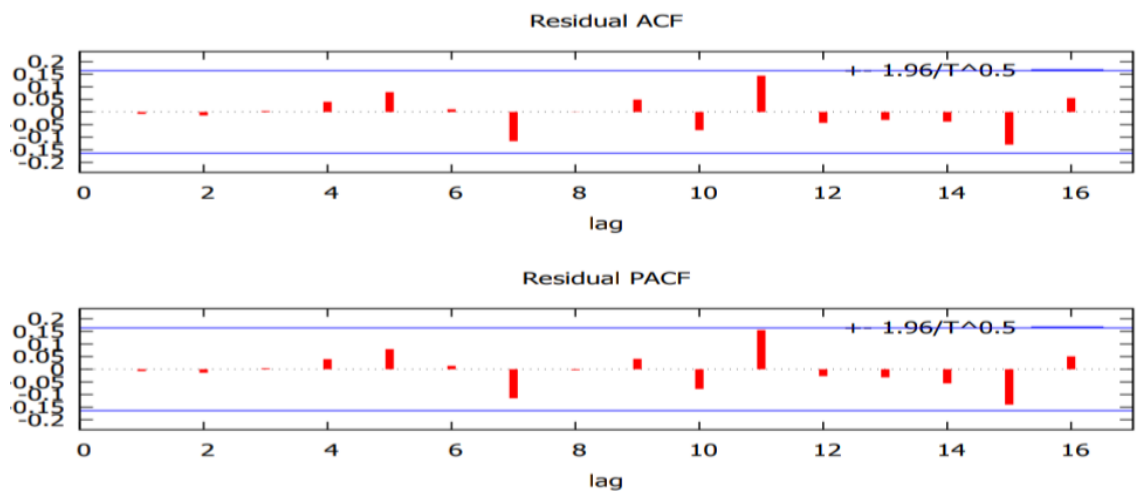

Fig.3 Autocorrelation and partial autocorrelation coefficient of cotton prices in Krishna market (level)

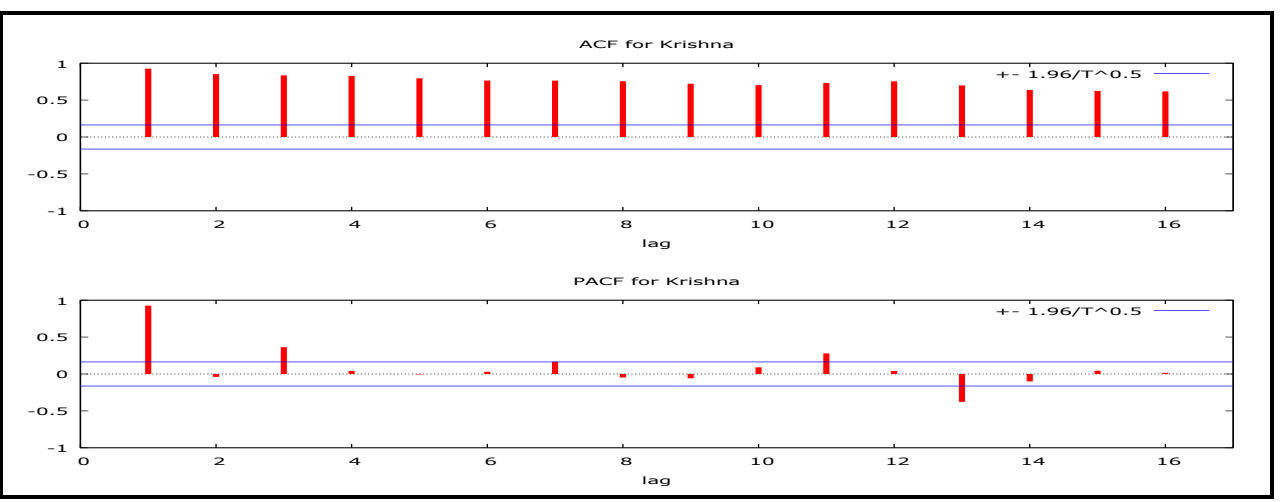


Fig.4 Autocorrelation and partial autocorrelation coefficient of $1^{\text {st }}$ difference series of cotton prices in Krishna market
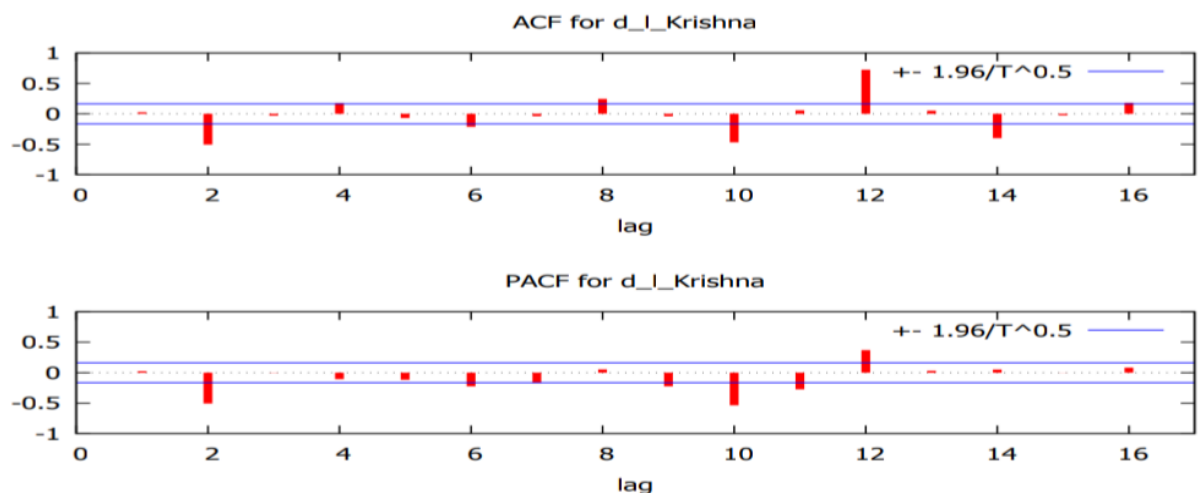

Fig.5 Autocorrelation and Partial Autocorrelation Coefficient of residual of ARIMA $(4,1,4)$ model for cotton prices in Krishna market
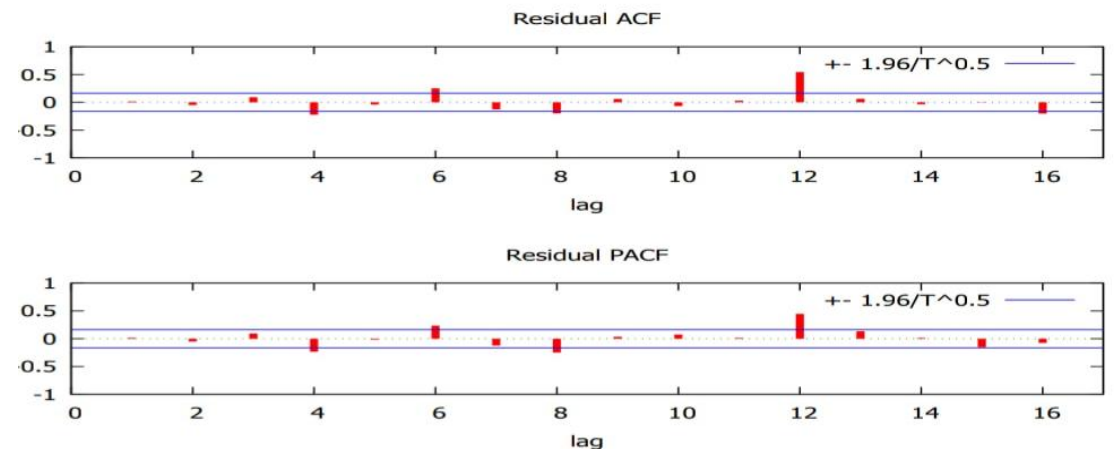

Forecasting of prices for cotton in Krishna Market:

\section{Identification of the model}

A model was identified for the prices of cotton in Krishna market. The monthly wholesale prices from April 2007 to March 2019 were used to estimate the ACF and PACF. The price data were tested for stationarity. It can be clearly seen from the table that there is fall in the values of $\mathrm{ACF}$ from 0.926 to 0.618. As observed from the analysis many values are different from zero and fall outside 95 percent confidence interval, indicating the price of cotton to be non-stationary. The analysis of partial autocorrelation coefficients of cotton have been depicted in the table 6 . The graphical presentation of ACF and PACF of table are given in Fig. 3. The partial autocorrelation function (PACF) took a fall after the $1^{\text {st }}$ lag period from 0.926 to 0.015 , from which the non-stationarity of the series can be inferred.

The table 6 shows that the autocorrelation and partial autocorrelation functions at lag 16 were significantly different from zero and fall outside the $95 \%$ confidence interval. $1^{\text {st }}$ difference of price data of cotton was done to make the series stationary.

The Augmented Dickey Fuller based unit root test procedure was carried out to check whether the price series of cotton were stationary or not. From the table 7 , it is 
observed that Augmented Dickey Fuller test values are above the critical value (1\%) given by MacKinnon statistical table at levels showing that the series are non-stationary by the presence of unit root. After the $1^{\text {st }}$ difference, the series become stationary which means the calculated values for the market are less than the critical value (1\%) and free from the consequence of unit root.

The results of Augmented Dickey Fuller (ADF) unit root test for cotton showed that the level of data was not stationary but their $1^{\text {st }}$ difference was found stationary. The graphical representation of ACF and PACF is given in the fig. 3 which confirms the results. Therefore, the value of $d$ in the ARIMA model was unity (1) because the $1^{\text {st }}$ difference was carried out only once to attain stationarity.

\section{Model estimation}

The best model was chosen from the various ARIMA models viz, ARIMA(4,1,4); ARIMA $(2,1,4) ; \quad \operatorname{ARIMA}(3,1,4) \quad ; \operatorname{ARIMA}(1,1,3)$; $\operatorname{ARIMA}(4,1,3)$ based on least Akaike Information Criterion (AIC) and Schwarz Bayesian Criterion (SBC). The models as identified above were estimated through the Marquardt procedure using SPSS 7.5 and SPSS 20 version of the SPSS package.

On comparing the alternative models on the basis of statistics such as Akaike Information Criterion and Schwarz Bayesian Criterion (SBC), it was inferred that both AIC(-203.42) and SBC (-183.69) were the least for ARIMA $(4,1,4)$ model from table 8. Hence ARIMA $(4,1,4)$ was the most representative model for the price of cotton in Krishna market (Fig. 4).

\section{Diagnostic checking}

The model verification is concerned with the residuals of the model to see if they still contain any systematic pattern which further could be removed in order to improve the chosen ARIMA, which has been analyzed by examining the autocorrelations and partial autocorrelation functions of various orders of the residuals of ARIMA $(4,1,4)$ up-to 16 lags were analyzed and presented in the table 9. The values of ACF and PACF varies from 0.015 to to -0.021 which shows the auto correlation and partial auto correlation functions at lag 16 were significantly different from zero and fall within the $95 \%$ confidence interval.

The graphical representation of ACF and PACF is given in the fig. 5 which also confirms the above results that there is no ACF and PACF that lies outside the interval. So we can say that the residual series is stationary. Thus it could be concluded that the selected ARIMA $(4,1,4)$ model was appropriate for forecasting the prices of cotton during the period under study.

It was observed from the analysis as mentioned in the table 10 that the model is valid by observing the Mean Absolute Percentage Error (MAPE) and Theil U statistics. Average MAPE was 7.54 percent for the year 2019 and Theil U was greater than 1 which showed the model $(4,1,4)$ is best for forecasting.

\section{References}

Mathews, G.A. and Tunstall, J.P.(eds). 1994. Insect pests of cotton. CAB International. pp.393.

James, C. 2008. Global stat 1us of commercialized biotech/GM crops. ISAAA Brief No.39.ISAAA. Ithaca. New York.

Rani,U., Reddy, G.P., Prasad, Y.E. and Reddy, A. 2014. Competitiveness of Major Crops in Post-WTO Period in Andhra Pradesh. Indian Journal of 
Agricultural Economics, 69(1):126141.

Reddy, A.A. 2012. Market Integration of Grain legumes in India: The case of
Chick pea Market, SAARC Journal of Agriculture, 10(1): 11-29.

\section{How to cite this article:}

Manne Sri Sandhya. 2020. Price Forecasting of Cotton in Krishna and Kurnool Districts of Andhra Pradesh. Int.J.Curr.Microbiol.App.Sci. 9(12): 1671-1683.

doi: https://doi.org/10.20546/ijcmas.2020.912.199 